\section{To What Extent is Experience Like Belief?}

ABSTRACT: In this paper, I argue that the connection between experience and belief is far closer than we might first suppose. In defending a broadly representationalist theory of perception,

for physicalist or functionalist accounts of mind.

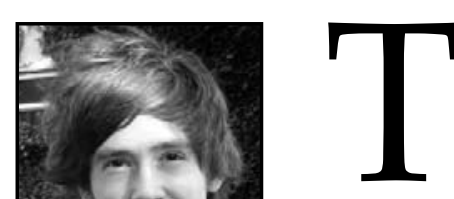

he extent to which experience is like belief might seem quite a perplexing question to pose. It might appear as intuitively obvious that the two notions are distinct: we apprehend various things in experience, and thereby infer our beliefs concerning the external world. Of course, it would be hard to deny the inextricable union between our beliefs and our experience of the world, but few would confidently asser a strict identity between them. But an answer to the question is an immensely important one, for if the connection between experience and belief is far more profound than our untutored intuitions might suppose, then we might be afforded citical insights into the nature of experience and pheno mology inelogy. argue that such a claim is made by the intentional or representational theory of perception and that with this theory, if its claims can be vindicated with the appropriate support, physicalist and functionalist theories of mind can accoun for certain properties of experience otherwise considered philosophically problematic.

Qualia theorists maintain that, in experience, we are directly aware of something other than the physical objects that we commonly take to lie therein. To clarify, the term "qualia" is used here to denote that supposedly peculiar irreducible phenomenal property of our conscious experience. With it we refer to the seeing of cor We can lean on Thomas Nagel's discussion of the problem and say that qualia are simply what it is like to have perceptual experiences. ${ }^{1}$ The existence of such properties has been considered a problem for most, if not all, physicalist or functionalist theories of the mind. For instance, it has been suggested, although not unanimously amongst dissenters, that qualia are non-physical properties of experience and, hence, cannot be accounted for in a physicalist model of the mind or reality. Furthermore, some have propounded the theory that two near-identical subjects who differed only in their phenomenal properties would nonetheless accord in the functional description attributed to them, thereby to announce the failure of functionalism to account for the existence of qualia.

As mentioned above, I propose that the representational theory of perception can account for the ostensible appearance of qualia in our conscious experience. The distinction between conscious and non-conscious experience is highly important, as it appears in some sense undeniable that the what it is like phenomenal property of experience can arise only in conscious perception. I cannot mentally pick out such a property in order for me to be struck by it in experience unless I am consciously aware of my experience. The act of referring to an object or property in or of my experience can only occur as an act of conscious awareness. With this in mind, we might consider a leading exponent of the representational theory of perception, John Searle. He discusses how "the content of the visual experience, like the content of the belief, is always equivalent to a whole proposition." ${ }^{\prime 2}$ This leads us to a more general tenet of representationalist theory, that in experience we are met with some sort of propositional content: that the world is in some sort of arrangement or state. In walking through my garden, any attentive remark I make on aspects of, say, the trees therin, involves some sentential expression with propositional content: "The trees look lovely;" "The leaves appear browner;" or even "A tree!" Construed in this manner, we might even go so far as to state that experience simply appears to actually be the uptake of belief. Again, as I consciously and attentively walk through the garden mentally remarking on my environment, beliefs regarding it are registered simply as perceptions. The perception, "the grass is green," appears to be no other than a belief regarding the grass and its purported color.

We can now see how one might relate this theory to an explanation of qualia. Experience affords us beliefs directly, as explicated above, where we apprehend propositional, representational content from our environment simply as various beliefs, such as "that car is yellow." Searle argues that we do not have experience of certain things such as qualia, for experience does not present its contents to us in that bare, unadulterated way. He deems it "a category mistake to suppose that when I see a yellow station wagon the visual experience itself is also yellow and in the shape of a station wagon. Just as when I believe that it is raining I do not literally have a wet belief, so when I see something yellow I do not literally have a yellow visual experience." ${ }^{3}$ The encroachment of qualia into theories of experience and perception seems upon Searle's account to have occurred due to a fundamental misconstruction of the way that we secure information from our surroundings. Any comment on the what it is like aspect of experience is simply a remark on the apprehension of propositional content from the experience of our environment and not an indication of the existence of phenomenal properties thereof. As Gilbert Harman also observes, “When you attend to...your experience of the redness of an apple, you are attending to...a quality of the apple. Perhaps this quality is presented to you....as an intrinsic quality of the surface of the apple. But it is not at all presented as an intrinsic quality of your experience. ${ }^{\prime \prime} \mathrm{He}$ suggests that in our fixation on the qualities found in our experience we find nothing but those of the objects fou-

2. John Searle, Intentionality (Cambridge: Cambridge University Press, 1983): 40.

2. John Searle,

4. Gilbert Harman, "The Intrinsic Quality of Experience" in Philosophical Perspectives, 4 (1990): 41. 


\section{To What Extent is Experience Like Belief?}

nd therein, not of the experience itself. What it is like to experience them is simply the act of representational perception

An opponent might rejoin with the observation that experience cannot be anything like belief, due to the existence and persistence of perceptual illusion. He might highlight how the experience of depth qualies a distinct and conting become confued due to the differ my experience will most directly present the objects held therein to have peculiar sizes or shape owing to their comparative distances, but will seem spread across my visual field equally: a tree viewed from fifty meters away might appear smaller in my visual field than a car of ten meter distance from me. Hence, it appears that we have a counterexample to the representational theory: we know that the tree is of a certain size compared with the car, irrespective of the way that they might appear to figure in our visual fields. On the representational theory, experience has suggested a certain propositional content, that the tree is smaller than the car, but here we feel inclined to disregard it and believe differently. Therefore, experience cannot be a form of belief. A representationalist response to the above counterexample would be that spatial location and comparative size are all presented to us as integral parts of the propositional content apprehended in such cases. It is not the case that we were once met with such a phenomenon and, unable to differentiate between the proximities of the car and the tree, saw them as comparatively larger or smaller. In order to understand such situations at all, to glean any kind of content from them so as to constitute conscious experience, we must already comprehend basic concepts such as the discrepancy between visual depth and comparative size. Harman observes that "to be presented as the same in size from here is not to be presented as the same in size, period," ${ }^{\prime 5}$ for if it were, our experience would be a perceptual chaos from which no content could be derived, and witt (ath which no action could be competently committed. Such is a case where it was, before we correlated perceptual depth with our direct visual experience, $i$ could only have been before we were fully conscious subjects, at the foundation of our cognitive development in infancy. In order for any successful purposive action to take place, spatial location must be immediately represented to us in perception. It would be plausible to state that this has been phylogenetically fixed through natural selection.

A remark made by J. J. Valberg on a related issue summates our response to the objection, as involving a dichotomy between two approaches to experience: "We can reason about experience, or we can be open to it - that is, to how things are within our experience [...] if we are open to our experience, all we find is in the world." only to arise from some sort of additional philosophical reasoning concerning our experience. Philosophical scrutiny might reveal peculiar aspects of our visual experience, but such scrutiny is utterly divorced from our more ordinary experience, which would otherwise regularly carry with it the representational content required for complete spatial understanding.

From a discussion of perceptual illusion we can move to an important part of the representational

5. Gilbert Harman, 38

6. J. J. Valberg, “"The Puzzle of Experience”" in The Contents of Experience: Essays on Perception, ed. T. Crane (Cambridge: Cambridge
Sam Hawke

theory of perception: that of accuracy conditions. In the apprehension of propositional content from our environment, the propositions given to us, like, "the grass is green," have accuracy conditions. As Searle puts it they have "conditions of satisfaction in exactly the same sense in which beliefs conception of the link between experience and belief: experience affords us propositional content, which we consequently take certain attitudes towards, such as belief. Presumably in order that we efficiently act within the world, our default attitude towards the propositional content given to us is one of belief. On encountering a car coming towards us rapidly, it is certainly optimal that our foremost attitude belief towards the proposition "there is a car coming towards me rapidly."

However, as mentioned above, many experiences are illusory or hallucinatory in nature. Most commonly, we cannot deny the visual experience of colored after-images upon glancing at the midday sun. This appears to be a counterexample to our discussion of all visual experiences having propositiol copilitating to our hitherto confidently propounded theory. However, for one, it is not that we observe such after-images without any corresponding content: we can remark that they are reddish in color or are of a particular recognizable shape. We can isolate the admittedly very simple content given by such experiences. We are able to form beliefs regarding them, or describe them at all, in virtue of their being similar in colour or shape to the objects that we veridically perceive. We can explain their having content as analogous to the content of the real objects that we regularly encounter in perceptual experience.

It is now worth reminding ourselves of the question regarding to what extent experience is like belief. As cases of hallucination and illusion demonstrate, the relation between the two cannot be one of stict identity. This is betina are veridical. Nor do we believe, upon taking a generous dose of hallucinogenic drugs, that the grass is purple, despite the relevant propositional content presenting the world to us in that way. Our default position of belief can be subverted due to various countermanding considerations, deliberations that lead one to believe illusion or hallucination to be taking place. This is where we must employ the notion of accuracy conditions. In the same manner that sentences have truth-conditions, they must satisfy or fail to satisfy in order that they be regarded as true or false, respectively, so too does the propositional content given by our environment. The proposition, "the grass is purple," presented to me in my experience, can be shown to be non-veridical via the testimony of the majority of all other normal perceivers or, if necessary, further scientific inquiry. Propositional content has accuracy conditions, specifications that may or may not be satisfied by Propositional content has accuracy conditions, specifications that may or may not be satisfied by
the way the world really is. Therefore, I know that the content "the grass is purple," as it figures in the way the world really is. Therefore, I know that the content "the grass is purple"
beliefs and the other propositional attitudes that I may take towards it, is false.

Following the remarks made above, the discussion of accuracy conditions enables us to finally expose the connection between experience and belief. Following the representational theory of perception, we have discussed how experience affords us propositional or representational content, in how we consciously perceive our surroundings as states of affairs attended to in conscious experience as whole propositions. These propositions are then taken as the content around which

7. Searle, 39 . 


\section{To What Extent is Experience Like Belief?}

one forms propositional attitudes such as beliefs. As above, it cannot be the case that such experience simply is belief, for in many cases the propositional content that we might haphazardly between experience and belief is the same bond that holds between $p$ attitudes: experience provides us with the propositional content around which we form our beliefs. In experience, I see that the grass is green, and thereby I believe that the grass is green. As previously asserted, we appear to be in a default position of belief, whereby it is our most natural inclination to take the majority of such propositional contents to be veridical and as directly apt for belief. But this default position can nonetheless be subverted by illusion and hallucination, and hence we must be circumspect as and when our suspicions abound.

I believe the representational theory can be given some sort of conceptual upholstery by the arguments of Wittgenstein against the possibility of a private language. A brief outline might construe it as stating first what appears to be a truth concerning the nature of language: that it is in essence, a normative and public affair. Sentences used in expressing propositions that concern publicly accessible states of affairs function in language by their rules of use, and this includes that contexts are applicable and what they can mean therein. These stipulations govern all spheres of language, including discussion of the alleged properties of private experience, qualia. Therefore, we must assess in what way we can normatively, publicly express propositions concerning them. Wittgenstein gives the now famous example of the diary: ${ }^{8}$ if a man were to attempt to formulate a language with which to express his private properties of introspective awareness, then the only criterion of correctness by which he can judge the proper use of the sign "S," the rules by which we all meaningfully employ expressions, is irreconcilable with the normativity of language, whereby we publicly describe and assess various states of affairs represented in propositions. It is, Wittgenstein remarks, as pointless as "someone [who bought] several copies of the morning paper to assure himself that what it said was true." The normativity of languages requires that we have the public assessment of all language use, and of which such a private diary of introspection is entirely bereft.

Robinson criticizes a decisive claim of Wittgenstein's argument. He states that owing to the determinate and recognizable character of the private features of introspection we can remember and reuse signs for them successfully. ${ }^{10}$ This, however, is merely to gloss over an important aspect of Wittgenstein's argument, that the memory cannot be an infallible guide for publicly estimable . Whective truth Robinson remarks that we simply do which occurs, presumably, regardless of a necessity for external corroboration. But the memory is a mere probabilistic tool: I am liable to trust my memory if I take myself to frequently make true judgements from whatever stock of memorised perceptions and concurrent beliefs I hold. Such a tool, lacking in the requisite certainty regarding the proper or improper application of words, cannot be used for the confirmation needed to form language. In assessing one's memory and the truth of judgements held therein one must look to external, public confirmation. As Wittgenstein remarks,

8. Ludwig Wittgenstein, Philosophical Investigations (Oxford: Blackwell Publishing, 2001): 78.

9. Wittgenstein, 79 .
Sam Hawke

I cannot simply peruse my memory in search of an infallible or objective confirmation of the time of my train: in trusting my memory, all I have to go on is some prior perceptual experience, which

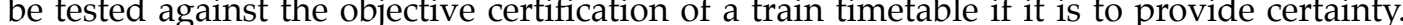
This lends support to a suggestion made earlier: that we can discuss our experiences in terms of qualia in virtue of our ability to discuss the physical objects external to us. Indeed, it now appears plausible to assert that the language of physical objects is ontologically prior to whatever language we use in attempting to discuss qualia, and that this might be necessarily so.

It is therefore plausible to suggest that experience cannot be said to directly involve qualia as properties of experience, but to concern external world and the way it is represented to us as holding propositional content. For I have interpreted Wittgenstein's argument in its weak form, and it must be stressed that we need not commit ourselves to its stronger interpretation, to the effect that we rule out all kinds of introspection. To return to qualia, one would state that really impoverished linguistic and conceptual competence, cannot apprehend propositional content from his environment. Such an assertion might be condemned as epistemically chauvinistic, as it regards to the cognitive potential of animals other than us, but it does seem at least requiring strong argument to ascribe propositional attitudes, as real mental events, to such animals. If it appears that we cannot regard non-linguistic animals as having the same kind of conscious experience as we have, one intrinsically involving the apprehension of propositional content, then it does not seem so easy to ascribe to their experience any phenomenal property regarding what it is like to have that experience. Without sufficient language, whatever experience non-linguistic animals have of the world cannot bear any phenomenal properties, as such properties appear only to arise due to the apprehension of propositional content.

It has not been denied that there is something being discussed by Nagel and others where they argue so virulently for the existence of phenomenal properties. However, the purported what it is like character of an experience appears to be more plausibly ascribed to the experience of objects themselves. The representational theory of perception shows that such properties appear only in virtue of the uptake of propositional content from the perceived environment, and hence should be considered as what it is like simply to experience objects and not what it is like to have an experience. It appears that the what it is like property of experience is entirely contingent on the ability of linguistically proficient animals such as humans to take in propositional content, are represented to us around which we form beliefs, unless this disposition is subverted by evidence against the purported veridicality of our perceptions. Therefore, there is no question as to the ontology or explanation of qualia: it remains to be shown by qualia theorists that qualia are properties of experience, rather than the way in which the representational theory of perception can now dispense with them as being. 